\title{
Europe draws up plans for a major programme of Moon exploration
}

Paris and Washington. Twenty-five years after the United States captured the imagination of the world with the Apollo Moon landings, the European Space Agency (ESA) is preparing to ask its space ministers to approve a long-term programme of expeditions designed to explore, exploit and colonize the Moon.

The agency hopes that such a 'return to the Moon' programme, which ministers will be asked to consider for funding next year, will rekindle international support for space exploration. The final phase could, as now planned, include an artificial ecosystem and a permanent manned presence.

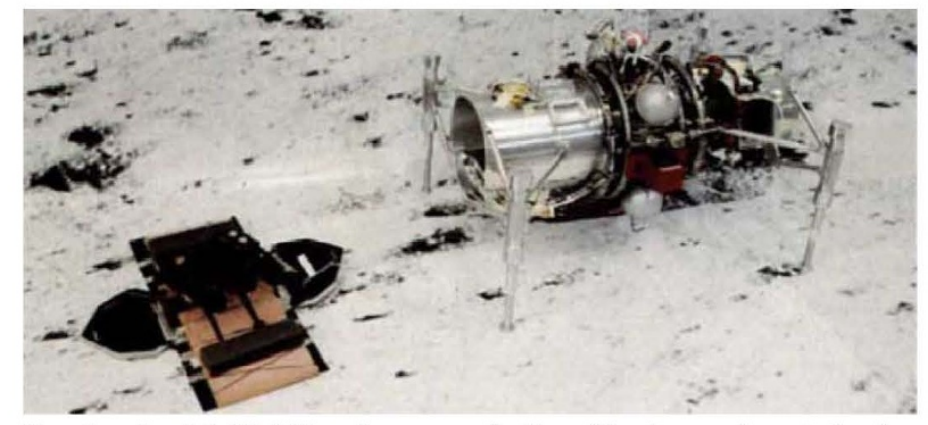

Heading back? NASA's micro-rover in New Mexico - (see below). mission (see Nature 369,$90 ; 1994$ ), to survey the surface and interior of the Moon over several years, using a wide range of remote sensing technology.

According to Julie Cave, an astronomer

nar resources and identify suitable sites for landing craft, as well as building a manned outpost on the far side of the Moon. New technology such as rovers would also be tested during this phase.

The second phase - a 'permanent robotic presence' would establish the Moon as a platform for automatic large scientific instruments and telescopes. Such instruments would take advantage of the Moon's stable surface, its lack of an atmosphere and the absence of electromagnetic interference emitted from Earth on the 'radio-quiet' far-side.

Astronomers say the Moon offers unique opportunities for

ESA is presenting its proposal as a longterm, open-ended venture. To make the programme appear less daunting and allow greater budgetary flexibility, the agency, based in Paris, has also designed it in four overlapping phases.

If funding is approved, the first 'exploratory' phase could begin within a decade. This would involve sending orbiting lunar observatories, such as the proposed MORO at University College London and a member of the MORO science team, this would be much more comprehensive than any previous survey, including that carried out recently by the US Clementine observer (see below). Planetary scientists, she adds, have become "immensely interested" in a new Moon mission following the preliminary data obtained from Clementine.

The observatories would also survey lu-

\section{US military backs new lunar mission}

Washington. Draft proposals from the European Space Agency for a long-term Moon programme (see above), combined with growing enthusiasm among the American military for a follow-up to the recent Clementine lunar mapping mission, may revive interest in lunar exploration at NASA.

NASA has abandoned its own lunar ambitions. Two-years ago the US Congress killed the agency's plans for a pair of US $\$ 100$ million lunar orbiters, and forced it to close the exploration office that was studying a return of man to the Moon.

The little momentum which exists for a US return to the Moon is coming from the Department of Defense (DoD). Although Clementine was designed to test hardware, and not as a science mission, it has filled the void in lunar exploration left by NASA.

Members of the military team which organized the Clementine mission are now lobbying for a Clementine 2 to test advanced propulsion and communications technologies not flown on the first mission.

They also argue that Clementine 2 could carry a rocket-propelled lander, based on hardware developed in the Pentagon's Strategic Defense Initiative (SDI). The lander, which has been built by the Air Force's
Phillips laboratory in New Mexico, recently deployed a two-pound micro-rover on a simulated lunar landscape.

The US $\$ 100$ million Clementine project is considered to have been a success, despite the software failure that has made it unlikely that the craft will rendezvous with an asteroid this summer as was planned.

The project has shown that deep space missions can be put together quickly and cheaply. Advocates argue that demonstration projects such as Clementine 2 are needed to recover some of the massive investment in advanced spacecraft technology made during the SDI programme.

Such advocates, who hope to obtain funding for a new mission from the Air Force or other armed forces, believe its approval will depend on persuading NASA to share the costs of the project and to provide the reasons for landing on the Moon. They hope, for example, that NASA will agree to use the craft to test advanced lightweight scientific instruments for planetary exploration.

But NASA has had to watch from the sidelines as the DoD earned the accolades for Clementine, and it is now eager to prove that it too can mount cheap and clever missions.

Tony Reichhardt ultraviolet and submillimetre imaging, and for very-low-frequency astronomy. It would also provide improvements measured in orders of magnitude in angular resolution and sensitivity at all wavelengths, they say.

In the third phase, the "utilization of lunar resources', robots would search for geological resources and seek ways to exploit them for use in establishing a manned outpost in the fourth phase.

ESA also says it should be feasible to manufacture propellants in situ for refuelling craft returning to Earth. This phase would also study the possibility of excavating an underground lunar base. Astronauts would be required to visit occasionally during this phase.

The final phase would involve establishing the first artificial ecosystem and permanent manned presence on another celestial body. This would provide the groundwork for exploration to Mars and beyond.

At a time when Europe is repeatedly scaling down its space plans because of its budgetary difficulties much of this may sound like science fiction. But officials in both Germany and France, for example, say that the proposals could provide a much-needed opportunity to look beyond immediate preoccupations and define a long-term space strategy.

At the same time, however, German officials add that the proposal is unlikely to receive support until Europe resolves outstanding budgetary problems, in particular the terms of its participation in the National Aeronautics and Space Administration (NASA)'s international space station.

The United Kingdom is less enthusiastic. British space officials point out that they are mainly interested in short-term commercial space applications and 'cost-effective' science missions, and that ESA's budget 